\title{
O JOGO DE REALIDADE ALTERNADA CURTO (SHORT ARG) COMO ESTRATÉGIA DE DISCUSSÃO DE CONCEITOS QUÍMICOS EM NÍVEL SUPERIOR
}

\author{
Thiago Cardoso de Deus ${ }^{\mathrm{a}}$ e Márlon Herbert Flora Barbosa Soares ${ }^{\mathrm{b}, *,(\mathbb{D}}$ \\ anstituto Federal de Educação, Ciência e Tecnologia de Goiás, 75131-457 Anápolis - GO, Brasil \\ 'Instituto de Química, Universidade Federal de Goiás, 74001-970 Goiânia - GO, Brasil
}

Recebido em 06/08/2019; aceito em 18/11/2019; publicado na web em 17/02/2020

\begin{abstract}
THE SHORT ALTERNATE REALITY GAME (SHORT ARG) AS A STRAGEGY FOR DISCUSSING CHEMICAL CONCEPTS AT COLLEGE EDUCATION. This paper presents the application of a Short ARG built to be applied in a single class, instead of a longer interval, as it is common in strategies such as ARG. ARGs are games based on role-playing experiences that involve role playing using a particular place, in this case, two classrooms and an education lab. Whereas ARG's characters are the participants/ players themselves, in this study, they were the Chemistry undergraduate students. The students/players were aimed of various clues and moments involving chemical concepts to find a lost student. We could notice ARG can be a teaching strategy, we mean, an alternative for conceptual discussion in the classroom as well as a diagnostic and formative assessment tool, characteristic of the use of games and recreational activities in teaching scientific concepts.
\end{abstract}

Keywords: ARG, pedagogical games; chemistry teaching.

\section{INTRODUÇÃO}

Os jogos se constituem como atividades prazerosas e divertidas, desde que se apresentem como uma ação livre e voluntária. Em uma sala de aula, seja de nível médio ou em nível superior, tal aspecto não é diferente. A utilização de jogos no ambiente escolar preconiza planejamento, rigor metodológico e compromisso com o que se deseja na busca de um amálgama entre o jogo e o processo educativo. Ele ainda pode possibilitar o diagnóstico do nível cognitivo do aluno e a discussão conceitual entre alunos e professores. Para isso, é necessário que o aluno se entregue gratuitamente ao jogo, que haja imersão, intencionalidade, equilíbrio entre os aspectos lúdicos e educativos do jogo, narrativas e desafios envolventes, que despertem a curiosidade, permitindo a discussão conceitual.

Autores como Chateau, ${ }^{1}$ Piaget $^{2}$ e Brougere $^{3}$ associam jogos e brincadeiras ao aprendizado. Soares ${ }^{4}$ afirma que durante a brincadeira, além da realidade objetiva, emerge-se também a "realidade lúdica", uma imersão no mundo da aventura, do imaginário, uma mistura de mundos que compreende aspectos afetivos e cognitivos. A brincadeira e o jogo não são um privilégio exclusivo das crianças, pois os jovens e adultos também brincam e jogam. Porém, no adulto existe de fato uma limitação das fantasias, muito por conta da sua visão de mundo, que permite imersões diferentes daquelas realizadas pelas crianças.

No que tange a utilização de jogos na educação, faz-se necessário um equilíbrio entre o que Kishimoto ${ }^{5}$ define como função lúdica e função educativa do jogo educativo. A primeira relaciona-se ao prazer, ao divertimento voluntário, enquanto a segunda relaciona-se ao aprendizado propriamente dito. Quando se pensa em elaborar ou aplicar um jogo educativo, deve-se observar a presença do equilíbrio entre as duas funções. Caso haja o predomínio de uma função sobre a outra, corre-se o risco de se ter nas mãos apenas um jogo, no caso de a função lúdica sobressair sobre a educativa, ou um apenas um material didático, no caso de a função educativa prevalecer sobre a lúdica. ${ }^{4}$

Cleophas, Cavalcanti e Soares ${ }^{6}$ apresentam uma contribuição, no sentido de uma melhor definição para o jogo utilizado em sala de aula, enquanto jogo educativo formalizado, utilizado na educação formal.

*e-mail: marlon@ufg.br
Os autores defendem que todos os jogos geralmente são educativos em algum momento da vida. Na sala de aula, esse jogo educativo é aplicado em um ambiente formal de educação. Logo, esse jogo educativo formalizado é chamado pelos autores de jogo pedagógico e é este termo que utilizaremos para nos referir ao jogo.

Em termos de jogos pedagógicos, nossa proposta tem como objetivo, a elaboração, aplicação e posterior análise de uma nova modalidade de Alternate Reality Game ( $A R G$ ) ou Jogo de Realidade Alternada, que denominamos Short $A R G$, ou ARG Curto, uma modalidade que apresenta características semelhantes aos ARGs tradicionais, porém, com menor duração e restrito ao ambiente escolar, para ser utilizado em aulas de Química, tradicionalmente em menor número nas escolas e consequentemente com menos tempo semanal. ARGs tradicionais, ou seja, mais longos, com envolvimento de discentes em intervalos de tempo maiores e também específicos para o ensino de química, mas não menos importantes estão presentes na literatura, destacando-se os trabalhos de Cleophas e colaboradores. ${ }^{7-10}$ Nesse sentido é importante discutir a natureza e características desse tipo de jogo.

Os ARGs são experiências que apresentam origem no termo computação ubíqua, que se refere um aumento das funções oferecidas pelos computadores no sentido de permitir sua utilização não só restrita ao gabinete ou uma caixa fixa, mas no sentido da integração de dispositivos, de uma interconexão imperceptível e presente em todos os lugares na sociedade. ${ }^{11}$ Dessa forma, o autor compreende que a ideia de computação ubíqua, no sentido da ação integrada, onipresente e pervasiva fomenta os pervasive games, ou seja, experiências potencializadas pelo uso das tecnologias da informação que transitam entre espaços físicos e virtuais.

Segundo Oliveira e Marinho, ${ }^{12}$ os ARG são jogos originados das experiências fundamentadas nos RPGs (Role Playing Games), jogos que envolvem a interpretação de papeis, com ações ao vivo no espaço urbano, que funcionam a partir de uma coletividade interna, porém, nos ARGs, os personagens são os próprios participantes, não há a necessidade de interpretar um papel.

O ARG se apresenta como uma narrativa que utiliza aspectos do mundo virtual tendo como base o mundo real, ou seja, transita entre realidades virtuais e realidades concretas. ${ }^{12}$ Esse tipo de jogo começou a aparecer no início do século XXI, sendo utilizado pela indústria 
de marketing para a divulgação e promoção de produtos ligados ao entretenimento. ${ }^{7,8}$ Para Andrade ${ }^{11}$ um dos aspectos interessantes do ARG é sua jogabilidade:

O desafio acontece em universo ficcional, que usa o mundo real como pano de fundo. Para conseguir jogar, o usuário deve procurar pistas pela internet, decodificando vídeos no YouTube, mensagens em blogs e fotologs, etc. Em alguns momentos, a pistas estão escondidas no mundo real - sob a forma de comerciais de TV, anúncios em revistas, manchetes de jornal, outdoors e até mesmo ligações telefônicas ${ }^{11}$ (p. 41).

Uma característica marcante dos ARGs é o uso das tecnologias: computadores, sites, blogs, smartphones, e-mail, etc. A narrativa deve contar uma história com começo, meio e fim, que envolve a resolução de enigmas presentes no mundo real e no mundo virtual, ou seja, alternam entre duas realidades. As ações dos jogadores podem influenciar os caminhos pelos quais a narrativa percorre. A tudo isso se adiciona a presença massiva das tecnologias na resolução dos enigmas e no andamento da aventura. Como resultado, temos um jogo pedagógico que conta com uma narrativa envolta em mistério, na qual os alunos precisam juntar pistas, resolver enigmas, elaborar teorias, discutir conceitos, procedimentos, colaborar e cooperar para que possam chegar ao final da aventura.

Bolsignore et al. ${ }^{13}$ afirmam que embora a primeira finalidade de utilização dos ARGs tenha se dado com propósitos de entretenimento, seu uso na educação vem ganhando espaço e se estabelecendo como ferramenta transformadora. Um olhar que se fundamenta na capacidade de desenvolver habilidades de pensamento crítico, alfabetização de informações e resolução colaborativa de problemas, promovendo uma espécie de inteligências coletiva.

Shaffer et al. ${ }^{14}$ afirmam que ao jogar, o aluno revela posturas e maneiras de trabalhar dentro de contextos específicos, ou seja, o ARG permite enxergar condutas e aspectos relacionados à personalidade, trabalho em grupo e atitude dos alunos, quando expostos a desafios. Há algumas características percebidas nos ARGs que apresentam estreita relação com a educação. Estas características contribuem para sua utilização no processo de ensino e aprendizagem. Cleophas ${ }^{7}$ aponta essas características de forma adaptada:

- Solução de problemas em diferentes níveis cognitivos, habilitando os alunos a compor seu próprio nível de aprendizagem dentro do jogo;

- Progresso e recompensas, o que permite que possa ser utilizado no processo de avaliação da aprendizagem;

- Dispositivos narrativos (personagem/enredo/história), o que favorece a inserção de temas atuais para uma análise crítico-reflexiva;

- Entrega regular de novos problemas e desafios, mantendo a motivação e interesse dos alunos sobre o jogo;

- Potencial para ser jogado por um grande número de participantes, o que não impede de ser jogado entre turmas que estejam em diferentes níveis de aprendizagem;

- Baseado em tecnologias simples, que estejam à disposição para favorecer a quebra de paradigmas sobre o uso das TIC;

- Os resultados podem influenciar os alunos no seu desempenho acadêmico;

Outro aspecto importante está ligado ao termo Alternate Reality Game. Assim como Cleophas, ${ }^{7}$ entendemos que a melhor tradução seria Jogo de Realidade Alternada. Há uma série de trabalhos na literatura que apresenta a tradução: Jogo de Realidade Alternativa. A partir da literatura em língua inglesa e das descrições dos vários ARG e seus aspectos teóricos, o que acontece de fato é que as realidades existentes, tanto a física, quanto a virtual, são alternadas no sentido de dar fluidez ao jogo, ou a proposta, ou a narrativa. Não há de fato uma realidade alternativa.

O ARG se passa em realidades físicas, mas também nas virtuais. As pistas e os desafios são realizados no mundo físico e no mundo virtual, de forma alternada, ou seja, ora os desafios se encontram em uma realidade a qual eles conhecem e vivem fisicamente, ora acontecem via computadores, telefones celulares, internet entre outros meios virtuais, aos quais também convivem. Dessa forma, entendemos que não se pode confundir a interpretação de papéis e a imaginação, típicas características do jogo, com realidades de fato alternativas, como por exemplo, jogos nos quais o jogador adentra um mundo virtual, construído para ser de fato, alternativo àquele o qual vive.

Neste trabalho, pretendemos apresentar um ARG para discussão de conceitos químicos em uma perspectiva piagetiana de análise. Dessa forma, faz-se importante uma pequena apresentação de alguns aspectos da teoria.

Destacamos que os jogos são para Piaget ${ }^{15}$ representações da imersão nos estágios do desenvolvimento, em um movimento de retroalimentação. Piaget ${ }^{15}$ afirma que a definição de jogo está diretamente ligada ao prazer funcional, à espontaneidade e à liberdade. Por meio da assimilação, o ser humano incorpora substâncias ou energias do meio à sua própria forma e, por meio da acomodação, o ser é modificado pelas transformações e imposições do meio.

Lefrançois ${ }^{16}$ afirma que a assimilação consiste em responder a situações utilizando conhecimentos já aprendidos ou que estão presentes no nascimento e que a acomodação consiste nas modificações realizadas pelo sujeito no objeto que foi, a princípio, assimilado. Uma relação que altera os esquemas dos indivíduos, um esforço adaptativo para superar o desnível da relação estabelecida. A relação entre a assimilação e a acomodação recebe o nome de equilibração.

Piaget ${ }^{17}$ apresenta três formas possíveis de equilibração, pelas quais se podem perceber a intensidade das relações entre as assimilações e acomodações, bem como a comunicação entre esquemas, sejam eles relativos a funções semelhantes ou bastante distintas. Elas são caracterizadas como equilibrações INTRA, INTER e TRANS, que se sucedem nessa ordem, dentro dos processos cognitivos.

Aguiar Jr. ${ }^{18}$ afirma que a primeira forma de equilibração é a do tipo INTRA e resulta da interação entre os esquemas que o sujeito possui e os objetos que ele pretende assimilar. Uma fase de análise de casos particulares insuficientemente ligados entre eles. São equilibrações mais simples, de esquemas mais próximos dentro da estrutura cognitiva. A equilibração da definição de densidade, por exemplo, no que se refere somente a razão entre massa e volume. Um segundo tipo de equilibração, denominada INTER, resulta da busca de um equilíbrio entre os esquemas de assimilação do indivíduo a partir de um jogo de assimilações e acomodações recíprocas. Nesse caso, a equilibração do conceito de densidade aplicado aos materiais e suas diferenças entre si, considerando-se a variação da massa e do volume dos materiais. A terceira forma de equilibração é denominada TRANS compreendendo a integração dos subsistemas coordenados produzindo uma nova totalidade, subordinando as informações da fase anterior a grandes estruturas de conjunto. ${ }^{18}$ (p.74).

Piaget ${ }^{17}$ afirma que esta forma de equilibração é diferente da segunda pelo fato de acrescentar uma hierarquia às relações colaterais experimentadas na equilibração INTER. Nesse caso, é a equilibração do conceito de densidade, aplicado não só a diferentes materiais assimilados na estrutura cognitiva, mas também aplicado a situações cotidianas, como a flutuação de um barco, entre outros conjuntos de esquema hierarquizados na estrutura cognitiva.

\section{MÉTODOS}

Este trabalho propõe uma aventura de Short $A R G$ para alunos de 
nível superior, avaliando e analisando o Short $A R G$ como estratégia de discussão de conceitos científicos e também como jogo pedagógico.

Em termos de referencial metodológico, este trabalho se apresenta como uma pesquisa qualitativa. Triviños ${ }^{19}$ aponta dois traços fundamentais para este tipo de pesquisa:

Por um lado, sua tendência definida, de natureza desreificadora dos fenômenos, do conhecimento e do ser humano; e, por outro, relacionada com aquela, a rejeição da neutralidade do saber científico ${ }^{19}$ (p. 125).

Utilizaremos, enquanto método qualitativo, a análise de conteúdo. Bardin $^{20}$ define a análise de conteúdo como um conjunto de técnicas de análise das comunicações que tem como objetivos a superação da incerteza e o enriquecimento da leitura. Franco ${ }^{21}$ afirma que o ponto de partida da análise de conteúdo é a mensagem que expressa um significado e um sentido, dentro de um contexto, seja ela verbal, oral ou escrita. Esta mensagem também pode ser gestual, silenciosa, figurativa, documental ou diretamente provocada. Para esta pesquisa, as mensagens analisadas foram as verbais, obtidas por meio de filmagens e áudios e posteriormente transcritas.

Nesse sentido, apresentamos, com base na observação das ações dos alunos, nossas inferências, apoiadas nas filmagens e áudios coletados. Uma relação que se apresenta dentro de contextos específicos da realidade e que, após uma evolução no modo de pensar sobre a análise de conteúdo, diz respeito não só ao emissor, mas também ao receptor. A delineação dos objetivos pode variar de acordo como tipo de abordagem utilizada. Em nosso recorte de pesquisa, utilizamos uma abordagem qualitativa, na qual as categorias emergiram ao longo da análise dos dados obtidos.

Em termos da organização da análise dos dados, existem três polos cronológicos: 1) a pré-análise, que consiste em uma fase de organização, de intuições, com o objetivo de operacionalizar e sistematizar as ideias iniciais, preparando-as para as ações de análise futuras. Aspectos como a importância da leitura flutuante, a escolha dos documentos, a exaustividade na análise dos materiais, a representatividade da amostra e sua homogeneidade precisam ser observados neste momento; 2) a exploração do material, que consiste na aplicação sistemática das decisões tomadas na fase anterior. Uma fase na qual as operações de codificação, decomposição e enumeração merecem destaque; 3) o tratamento dos resultados obtidos e sua interpretação, que consistem em tornar os resultados significativos e válidos, recomendando-se a utilização de técnicas estatísticas e testes de validação. De posse dos resultados significativos e fiéis, podemos enfim, fazer as inferências e discutir as interpretações. ${ }^{20}$

Franco $^{21}$ afirma que a análise se inicia no conteúdo manifesto e explícito, o que não significa que ela deva se concluir nele, é preciso investigar o oculto, as entrelinhas, a fim de se realizar uma análise mais objetivada, mas próxima da "coisa em si". Nesse sentido, analisamos a transcrição das falas dos alunos, levando em conta alguns aspectos observados em nossa ação como professor e na análise dos vídeos, que nos permitiu observar aspectos que não aparecem nos áudios.

\section{A aventura de Short $A R G$}

Para introduzir o assunto aos jogadores, apresentamos uma breve descrição do Short ARG, deixando claro que todas as discussões presentes na aventura seriam gravadas e filmadas. As filmagens e gravações auxiliam o professor na análise das discussões e ações dos alunos ao longo da aventura.

A aventura procura levar os alunos a desvendarem o desaparecimento de um aluno do curso de licenciatura em Química chamado
Jhon Holmes Silva. Uma breve descrição do perfil de Jhon foi apresentada aos alunos, informações que poderiam ser úteis para desvendar o mistério do seu desaparecimento. Jhon era um aluno do sétimo período do curso de Licenciatura em Química, tímido, antissocial, alto, acima do peso e que usava óculos, além disso, gostava muito de filmes e séries de investigação. Informamos aos alunos que a última vez que Jhon foi visto, ele estava no laboratório de química.

Temos, portanto, um primeiro cenário a partir do qual os alunos iniciam a aventura. Chegando ao laboratório, o professor se reúne com o grupo e tira uma selfie com os alunos. Analisando a imagem da foto, os alunos enxergam um jaleco com as iniciais JHS. Ao examinarem o jaleco, encontram um bilhete que diz: "mensagem encaminhada para a professora" e um número de telefone. Após examinar a selfie e encontrar o jaleco, os alunos são instados a entrar em contato com o número encontrado. Desde o início da aventura as tecnologias da informação e comunicação se fazem presentes. Após entrarem em contato utilizando o aplicativo whatsapp, os alunos recebem a resposta da professora afirmando que Jhon havia lhe enviado uma mensagem no dia anterior. A mensagem dizia: "olá pessoal, o Jhon me enviou uma mensagem dizendo que havia descoberto uma coisa importante, que queria se encontrar comigo com urgência para conversarmos. Disse a ele que só poderia hoje, só que ele não apareceu mais, estou preocupada"..."ah...ele também me mandou outra mensagem muito esquisita que dizia "sala de informática, computador 2, arquivo X, senha (o de densidade entre 8 e 9 g. $\mathrm{cm}^{-3}$ mais pista, vide o experimento da densidade)".

A pista encontrada levou os alunos a discuti-la e consequentemente vasculhar o laboratório em busca de evidências. Sobre a bancada, os alunos encontraram três materiais, um pedaço de cobre, uma bola de isopor e uma bucha de parede, conforme Figura 1.

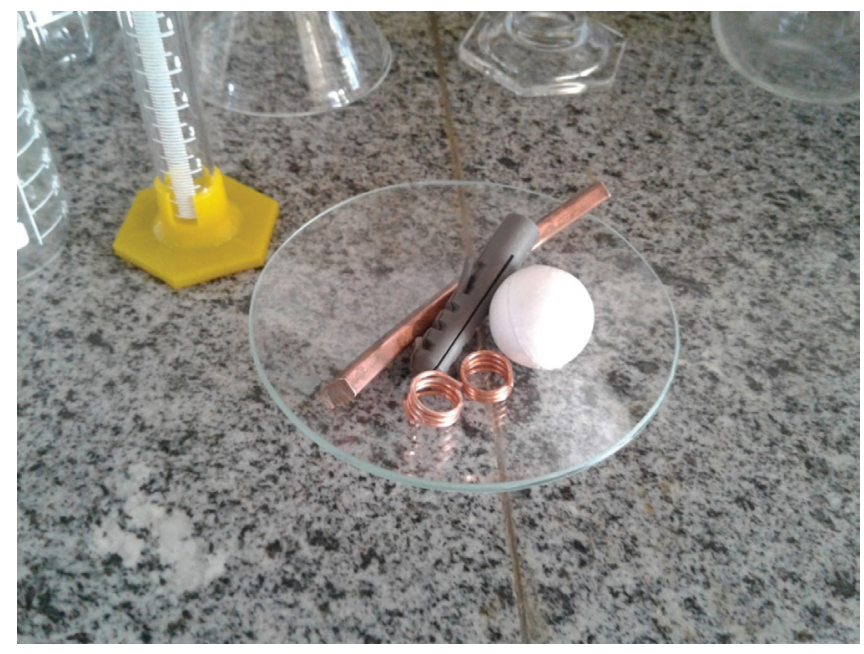

Figura 1. Materiais cujas densidades deveriam ser determinadas

A ideia é que os alunos determinassem a densidade de cada um dos três objetos para encontrar a primeira parte da senha que abriria $\mathrm{o}$ arquivo $\mathrm{X}$. Os alunos também deveriam enviar um áudio com as gravações das discussões referentes ao experimento para um e-mail, para receber a segunda parte da senha.

O elemento cuja densidade se encontrava na faixa entre 8 e 9 g. $\mathrm{cm}^{-3}$ era o cobre, a segunda parte da senha era "leito", portanto, a senha "cobreleito" abre o arquivo X. Ao abrir o arquivo no computador, os alunos encontraram um texto cujo título era: "A beleza dos fogos de artifício", além de quatro objetos de aprendizagem (vídeos) sobre modelos atômicos e, no final do texto, a seguinte informação “armário 1, frascos 1 e 2". 
Os alunos então examinaram o texto, os objetos de aprendizagem e se concentraram na próxima pista. No armário enumerado, estão duas soluções, uma incolor e uma de cor azul. No rótulo das soluções a seguinte pista: "decifra-me ou não verás a beleza da minha luz interior". A pista serve para levá-los a um teste de chama. Após verificarem a cor das chamas dos metais presentes nas soluções, os alunos novamente deveriam enviar a discussão do experimento para um e-mail e tentar relacionar o fenômeno do teste de chama com o texto e os vídeos encontrados no arquivo X. Como resposta, os alunos receberam outras pistas: uma foto de um pano próximo a um frasco de clorofórmio; uma foto de um corpo sendo carregado; uma foto de uma corda; uma foto de um esparadrapo. As imagens só poderiam ser visualizadas com um leitor de QRcode. Tal código é apresentado na Figura 2.

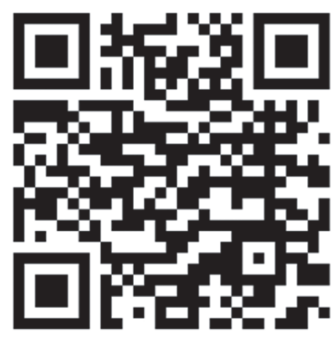

Figura 2. QR Code apresentado aos alunos na Aventura

No e-mail também havia um texto que dizia: "viu como minhas cores são bonitas? Elas também estão na sala ao lado, estou lá, apesar de ser muito avançado para a tecnologia do lugar".

Os alunos examinaram a sala ao lado em busca de alguma pista e encontraram dois pincéis para quadro de tinta. Na sala havia apenas um quadro para giz. Nos pincéis, os alunos encontraram um desafio que consiste em determinar métodos para a separação dos componentes de uma mistura contendo areia, serragem, sulfato de cobre, limalha de ferro e pedaços de brita. Após enviar o áudio ou vídeo com a discussão sobre o experimento para um e-mail os alunos receberam as últimas pistas: uma imagem de um frasco de lança perfume; um e-mail enviado pela coordenação do curso a um aluno com o seguinte conteúdo: "Boa tarde senhor Anderson Santos. Esta coordenação o aguarda para prestar esclarecimentos sobre uma suposta denúncia envolvendo o senhor"; e uma localização.

De posse das pistas os alunos se reúnem em uma sala e, de forma colaborativa, apresentaram suas pistas para desvendar o desaparecimento. Os alunos chegaram à conclusão que Jhon havia descoberto que um professor, de nome Anderson estaria utilizando o laboratório de Química para sintetizar lança-perfume. Assim, teria enviado uma mensagem à professora dizendo que queria falar pessoalmente para ela e que tentou entrar em contato com a coordenação, chegando a mencionar o nome Anderson, mas antes de terminar a denúncia a ligação caiu. Naquele momento ele havia sido sedado com clorofórmio, amarrado, amordaçado e levado para algum lugar, o qual teve a localização obtida como pista.

A localização era do lado de fora do prédio, quando chegam ao local os alunos encontram um bilhete, dentro de um porta-malas de um carro, com uma frase externa: "leiam na sala para todos os grupos". O bilhete dizia: "muito bem, vi que vocês são bons em seguir pistas, estão de parabéns. O que vocês não sabem é que na verdade não houve sequestro algum, eu apenas estava realizando um experimento com vocês. Consegui todos os dados que queria. Obrigado. Jhon Holmes Silva".

A Tabela 1 apresenta uma descrição das principais pistas da aventura descrita e as ações que os alunos deveriam realizar durante sua realização.
A Figura 3 apresenta o professor/orientador da aventura, realizando as discussões finais a partir das hipóteses dos alunos sobre o desaparecimento de Jhon Holmes Silva.

O Short ARG foi aplicado em uma turma da disciplina de Didática para Licenciatura em Química do curso de Licenciatura em Química da Universidade Federal de Goiás. No caso presente, a aventura foi aplicada para 12 alunos (A1, A2...), divididos em 3 grupos (G1, G2 e G3), de modo que as falas pudessem ser identificadas em cada um dos grupos. Por exemplo, G1A4, ou seja, aluno 4 do grupo 1. $\mathrm{O}$ professor aplicador da aventura foi identificado com a letra P. Quando nos referimos a um grupo de alunos que respondem ao mesmo tempo, utilizamos a letra T. Os dados foram colhidos por meio de filmagens, posteriormente transcritas, diário de campo, áudios dos alunos em celulares, gravados durante as discussões em grupo e posteriormente transcritos, além de conversas informais com os participantes. A aventura utilizou três espaços físicos: duas salas de aula e um laboratório de ensino.

No decorrer da aventura, os alunos transitaram por todo o espaço em busca de pistas que os ajudassem a resolver o enigma do desaparecimento de Jhon, sempre com o auxílio das tecnologias da informação e comunicação. Vale salientar que para este trabalho analisaremos as ações referentes às pistas/momentos 4, 6 e 7, descritas na Tabela 1, que tratam dos experimentos envolvendo conteúdos de química.

Por meio da análise de conteúdo, emergiram da análise dos instrumentos de coleta de dados, duas grandes categorias, a saber: 1) Discussão Conceitual e; 2) Função Lúdica do Short ARG. Para este trabalho, iremos no concentrar na análise da primeira grande categoria, conforme apresentada na Tabela 2, que compreende as discussões relativas aos experimentos da densidade, teste de chama a análise de objetos de aprendizagem (vídeos de modelos atômicos).

\section{RESULTADOS E DISCUSSÕES}

A categoria Discussão Conceitual compreende dois aspectos, o primeiro corresponde à discussão dos conceitos químicos envolvidos nos experimentos e o segundo se refere à manipulação de equipamentos de laboratório. Entendemos que para melhor entendimento da aventura, as subcategorias acabam por se mesclar e serão discutidas de forma concomitante.

No primeiro experimento, três objetos estão sobre uma bancada, um pedaço de cobre, uma bola de isopor e um polímero (bucha de parede), os alunos precisam discutir como proceder para determinar a densidade dos objetos. Dos quatro grupos analisados, dois compreendem o conceito em nível microscópico, apresentando uma preocupação com as medidas de volume e massa, entendendo que estas podem influenciar no resultado do experimento:

$$
\text { “Quer fazer de novo? Com mais...precisão?” (G2A2) }
$$

Alguns alunos não sabem como determinar experimentalmente a densidade de um objeto. Dois grupos tiveram que recorrer à internet para realizar o procedimento, inclusive quanto ao procedimento experimental, o que evidencia certa dificuldade dos alunos com a experimentação, em especial a investigativa. Suart e Marcondes ${ }^{22}$ apontam para dificuldades dos alunos com experimentação em função da atuação empirista e unilateral de muitos professores.

As atividades experimentais, tanto no ensino médio como em muitas universidades, ainda são muitas vezes tratadas de forma acrítica e aproblemática. Pouca oportunidade é dada aos alunos no processo de coleta de dados, análise e elaboração de hipóteses. O professor é o detentor do conhecimento e a 
Tabela 1. Descrição da aventura Short ARG

\begin{tabular}{cll}
\hline $\mathrm{N}^{\mathrm{o}}$ da Pista/Momento & \multicolumn{1}{c}{ Descrição } & Ação \\
\hline 1 & Selfie com o grupo na porta do laboratório & Examinar as selfie. \\
\hline 2 & Jaleco com as iniciais do aluno (JHS) & Examinar o Jaleco. \\
\hline 3 & Número de telefone de uma professora. & Entrar em contato. \\
\hline
\end{tabular}

Resposta, via aplicativo whatsapp: "olá pessoal, o Jhon me enviou uma mensagem dizendo que havia descoberto uma coisa importante, que queria se encontrar comigo com urgência para conversarmos. Disse a ele que só poderia hoje, só que ele não apareceu mais, estou preocupada"..."ha...ele também me mandou outra mensagem muito esquisita que dizia "sala de informática, computador 2 , arquivo $X$, senha (o de densidade entre 8 e $9{\mathrm{~g} . \mathrm{cm}^{-3}}^{-}$pista, vide o experimento da densidade".

\begin{tabular}{lll}
\hline 5 & Segunda parte da senha (leito) & Juntar as partes e abrir o arquivo X. \\
\hline 6 & $\begin{array}{l}\text { Arquivo X: um texto sobre a beleza dos fogos de artifício; quatro } \\
\text { objetos de aprendizagem sobre modelos atômicos; mensagem: } \\
\text { "armário 1, frascos 1 e 2". }\end{array}$ & $\begin{array}{l}\text { Examinar o texto, os objetos de aprendizagem e a mensagem; } \\
\text { Procurar os frascos na prateleira. }\end{array}$ \\
\hline
\end{tabular}

7 "decifra-me ou não verás a beleza da minha luz interior"; mensagem solicitando aos alunos que enviassem a discussão dos experimento para um e-mail.

QRcodes contendo: uma foto de um pano próximo a um frasco de formol; uma foto de um corpo sendo carregado; uma foto de uma corda; uma foto de um esparadrapo; Mensagem: "viu como minhas cores são bonitas, elas também estão na sala ao lado, estou lá, apesar de ser muito avançado para a tecnologia do lugar".

Canetões de tinta com a mensagem: "determinar métodos para a separação dos componentes e uma mistura contendo areia, 9 serragem, sulfato de cobre, limalha de ferro e pedaços de brita. Enviar o áudio ou vídeo com a discussão sobre o experimento para um e-mail os alunos

QRcode com imagem de um frasco de lança perfume; um e-mail enviado pela coordenação do curso a um aluno com o seguinte conteúdo: "Boa tarde senhor Anderson Santos. Esta coordenação o aguarda para prestar esclarecimentos sobre uma suposta denúncia envolvendo o senhor"; e uma localização.
Executar o teste de chama para verificar a cor das chamas das soluções;

Enviar as discussões para o e-mail.
Abrir as fotos com o Leitor de QRcode e examiná-las; Procurar na sala ao lado alguma pista de acordo com a mensagem. obtidos com a pista; Enviar áudio e vídeo das discussões para um e-mail;

Realizar o experimento da separação de misturas;

Fim da aventura no laboratório.

Reunir todos os grupos em uma sala;

Colocar todas as pistas;

Solucionar o caso;

Encontrar Jhon na localização enviada.

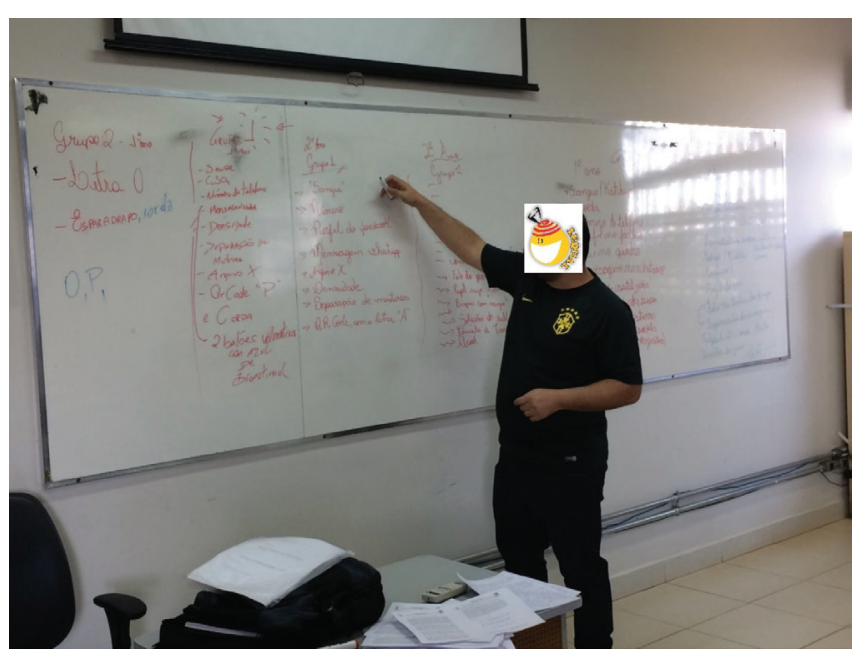

Figura 3. Professor promovendo a discussão após a aventura

ciência é tratada de forma empírica e algorítmica. O aluno é o agente passivo da aula e a ele cabe seguir um protocolo proposto pelo professor para a atividade experimental, elaborar um relatório e tentar ao máximo se aproximar dos resultados já esperados ${ }^{22}$ (p. 51).
Tabela 2. Categoria de análise discutida no trabalho

\begin{tabular}{|c|c|c|}
\hline Categoria & Subcategorias & $\mathrm{O}$ que pretende analisar \\
\hline \multirow[t]{2}{*}{ Discussão Conceitual } & $\begin{array}{c}\text { Discussão do } \\
\text { Conceito Químico }\end{array}$ & $\begin{array}{l}\text { Como os alunos discutem } \\
\text { o conceito, nível de enten- } \\
\text { dimento deste, avaliação } \\
\text { da aprendizagem e con- } \\
\text { ceitos prévios. }\end{array}$ \\
\hline & $\begin{array}{l}\text { Manipulação em } \\
\text { Laboratório }\end{array}$ & $\begin{array}{l}\text { Como os alunos se portam } \\
\text { em laboratório, além do } \\
\text { comportamento observá- } \\
\text { vel em relação a mani- } \\
\text { pulação de experimentos. }\end{array}$ \\
\hline
\end{tabular}

A determinação da densidade do pedaço de cobre foi a parte em que os alunos tiveram menor dificuldade. Após discussões, chegaram à conclusão de que deveriam medir a massa do pedaço de cobre e posteriormente, submergi-lo em uma proveta contendo um volume de água definido e anotar o deslocamento de volume. Nesse sentido, em termos da teoria piagetiana, podemos afirmar que o conceito foi bem assimilado e acomodado pelos esquemas dos alunos. No geral, a determinação da densidade de um corpo sólido mais denso que a água nos parece o modelo mais bem acomodado pelos alunos.

Um erro recorrente nos quatro grupos consiste na utilização do termo "pesar" para se referir a medição da massa dos materiais cujas 
densidades deveriam ser determinadas. Para esses alunos, os conceitos de peso e massa fazem parte de um mesmo esquema, mesmo que tenham estudado, em disciplinas de física, a diferença entre os conceitos. Piaget ${ }^{17}$ define como assimilação deformante $o$ fato de o sujeito entrar em contato com o objeto, e não conseguir assimilar os atributos dele, para estabelecer as diferenciações necessárias, como consequência, temos a manutenção do esquema pré-existente ou a formação de um esquema diferente do esperado. As falas a seguir exemplificam as assimilações deformantes e dificuldade com a experimentação investigativa:

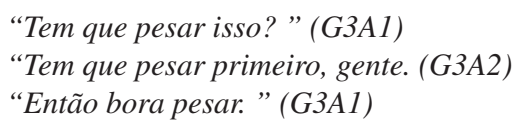

No geral, a definição de densidade, mesmo em diferentes áreas, implica uma relação entre duas grandezas, mas nem sempre é assimilada e acomodada corretamente pelos alunos, o que pode dificultar a criação de esquemas mentais, resultando em assimilações diferentes das pretendidas para a propriedade em questão. A formação de esquemas que resultam em modelos mentais distorcidos ou diferentes dos esperados compromete a aprendizagem, na medida em que precisam ser modificados, o que nem sempre acontece, mesmo com a intervenção do professor, uma vez que podem ocorrer assimilações deformantes, resultado de incorporações egocêntricas, ou seja, assimila-se aquilo que satisfaz ao seu eu, em vez da realidade posta. ${ }^{17}$ Por outro lado, entendemos que o uso da palavra pesar é comum entre os estudantes e até professores. Mesmo entendendo que as balanças atuais de alguma maneira trabalham com a força peso, recomendamos que o termo medir a massa parece mais adequado.

A proposta do experimento da densidade era que os alunos pudessem discutir os conceitos científicos relativos ao conceito, expondo o que de fato, eles entendem sobre a propriedade. Neste aspecto, o Short $A R G$, enquanto jogo pedagógico possibilitou a ampla discussão do conceito, de forma livre e voluntária, umas das características evidenciadas quando da utilização de jogos pedagógicos em sala de aula. ${ }^{4}$

Ainda no experimento da densidade, antes de determinar o volume da bola de isopor, os alunos do grupo 1 e do grupo 2 rapidamente procuram estabelecer métodos que envolvam conhecimentos matemáticos:

“Medir o diâmetro da bola de isopor, pesar ela." (G1A1)

“Qual o volume da esfera? Pi, $r$, ao..." (G2A1)

As afirmações acima mostram que os alunos conseguem estabelecer relações entre esquemas do tipo INTER, para determinar o volume de objetos com formato de figuras geométricas, além da utilização do deslocamento de líquido, muito comum em laboratórios de química. Nesse caso, temos uma evidência de equilibrações do tipo INTER, a comunicação entre esquemas por meio de assimilações e acomodações recíprocas, porém, isso aconteceu por um breve período. Como o conceito não está totalmente acomodado dentro do esquema que trabalha a linguagem matemática, os alunos desistem de utilizar o raciocínio em função da utilização de um esquema mais bem acomodado na estrutura cognitiva, o do deslocamento de volume. Como consequência, a equilibração INTER deixa de prosseguir, pois não há assimilação recíproca.

Sob esse aspecto, o Short ARG pode proporcionar uma oportunidade para o professor observar as deficiências nos esquemas dos alunos e a partir dessa observação, promover desequilíbrios que permitam a formação de novos esquemas ou o a melhoria dos esquemas já existentes, no sentido de possibilitar assimilações e acomodações que permitam a ocorrência de equilibrações INTRA, INTER E TRANS. ${ }^{17}$ No sentido da plena utilização do pensamento formal, é de extrema importância que o aluno, enquanto ser humano, consiga manter o fluxo entre as três formas de equilibração, permitindo partir de características particulares dos fenômenos, possibilitar relações entre esquemas e a hierarquização de informações.

Na determinação da densidade do cobre, propusemos que dois pedaços do metal fossem utilizados para um melhor deslocamento de volume. Neste sentido, quando questionados se haveria alteração na densidade caso fossem utilizados dois pedaços de cobre, alguns alunos afirmaram que sim em um primeiro momento, porém, o professor continua os questionamentos na tentativa de fazer com que os alunos entendessem que por se tratar de um mesmo material, um aumento da massa também ocasionaria um aumento proporcional de volume e consequente manutenção do valor da densidade, ou seja, que a densidade se trata de uma propriedade intensiva da matéria.

A determinação da densidade da bola de isopor foi a que os estudantes encontraram maior dificuldade, uma vez que o isopor é menos denso que a água. Depois de muita discussão em grupo, com a participação do professor, os alunos chegam à conclusão que, se utilizassem outro objeto para submergir a bola, poderiam ter êxito. Um grupo não levou em conta que o volume do objeto deveria ser descontado. Ao final, os grupos conseguiram, com a ajuda de um pedaço de cobre, afundar a bola e calcular seu volume, descontando o volume do pedaço de cobre.

Diante das dificuldades em determinar o volume da bola de isopor, os alunos tentam estabelecer raciocínios lógicos, em termos das operações formais, realizando comparações entre as densidades dos materiais, de acordo com a sua composição química. Nesse sentido, percebemos que os alunos conseguem estabelecer equilibrações do tipo INTER, uma comunicação entre esquemas próximos, no caso, os relacionados à densidade dos materiais em função da sua constituição, bem como experiências vivenciadas ao longo da vida, sejam elas de senso comum ou científicas. As falas a seguir exemplificam a discussão entre os alunos de um mesmo grupo, no sentido da comparação entre as densidades dos materiais:

“Não...então...eu acho que assim...a gente já encontrou... não precisa calcular a desse aî” (G2A2)

"Vai perder tempo uai” (G2A3)

Na determinação da densidade do polímero (bucha de parede), grande parte dos alunos não levou em conta que parte do objeto não estava submerso, o que leva a uma medição incorreta do volume. Alguns, ao perceber a medição incorreta, sugeriram colocar outro objeto que pudesse manter o polímero submerso, isso após determinarem o volume da esfera de isopor pelo mesmo método. Vale salientar que o Short ARG enquanto jogo pedagógico permite a aprendizagem colaborativa, ou seja, a discussão em grupo, na perspectiva da resolução coletiva do problema. Em alguns casos, percebemos também a presença da aprendizagem cooperativa, na qual o professor, muitas vezes representado por um aluno com maior conhecimento do assunto, delega funções aos outros membros do grupo e explica alguns conceitos ainda não acomodados pelos alunos.

No que diz respeito ao conceito de densidade, os esquemas que mais parecem estar acomodados são aqueles que se referem às relações entre objetos cuja densidade é relativamente menor ou maior que a da água. As densidades intermediárias, isto é, com valores próximos a densidade da água, não parecem estar assimiladas pelos alunos. Neste caso ou foram parcialmente assimiladas com esquemas restritos que acabam não funcionando como conceitos prévios 
adequados ou ainda foram assimilados de maneira deformante, ou seja, aparentemente se assemelha ao conceito, no entanto, de forma superficial, não abrangente e não recíproca. ${ }^{17}$

Após abrirem o arquivo $\mathrm{X}$, os alunos têm acesso a algumas informações que poderiam ajudar a compreender o teste de chama, como vídeos de modelos atômicos. O primeiro vídeo mostra átomos no modelo atômico de Dalton se ligando para formar a molécula de água. O segundo vídeo mostra o modelo atômico de Thomsom, um giro de 360 graus no modelo e a câmera "adentra" no modelo para mostrar que os elétrons estão não só na superfície, mas em toda a parte do átomo. O terceiro modelo mostra um giro em torno do átomo de Rutherford e o quarto vídeo mostra um giro sobre o modelo atômico de Bohr e a seguir uma ênfase na transição eletrônica.

Na medida em que os alunos visualizam os vídeos, o professor solicita que eles comentem sobre eles. O objetivo era que os alunos pudessem estabelecer uma relação entre os modelos atômicos e o texto, para deduzirem que na próxima pista seria importante a realização de um teste de chama, para descobrir a cor das chamas dos metais presentes nas soluções e encontrar os pincéis com as cores das chamas. Nesse aspecto, percebemos interpretações errôneas de modelos atômicos e sobre o processo de emissão de luz por meio de transições eletrônicas. As falas a seguir elucidam os aspectos apontados:

\author{
“Quando o elétron vai pra camada de fora.” (G1A2) \\ “Ele emite luz.” ( G2A3) \\ “Não quando ele volta que ele emite luz.” (G2A2)
}

"Não, quando ele é excitado ele emite luz, depois ele volta ao estado normal dele." (G2A3)

"Então, como você vai excitar ele pra descobrir, pra testar?" (G2A4).

Notamos uma deficiência no esquema de modelos atômicos do estudante, em especial devido à assimilação errônea do processo de emissão de luz visível por parte dos átomos, que para ele se dá quando o elétron é promovido a um nível superior de energia. A acomodação correta do conceito, em termos do modelo atômico de Bohr, se dá na medida em que o elétron recebe quantidade de energia específica, o que gera um comprimento de onda característico.

No grupo 3 também observamos inconsistências conceituais. Um vídeo mostra a câmera passando por dentro de um átomo de Thomsom para mostrar que, de acordo com aquele modelo, os elétrons estão dentro da esfera positiva e não apenas na superfície dela, então A3 interpreta este fato como uma sobreposição de nuvem eletrônica.

$$
\text { “Sobreposição de nuvem, caraca.” (G3A3) }
$$

Nesse caso, entendemos que a acomodação do modelo atômico se deu em um nível bidimensional, como aparece em muitos livros de ensino médio, o que resultou em um esquema "carente" de representação tridimensional, um erro que muitos alunos cometem ao interpretar o modelo atômico de Thomson. Melo e Lima Neto ${ }^{23}$ argumentam que a química é uma ciência baseada em modelos e que isso muitas vezes não é abordado pelo professor e pelos livros didáticos, como consequência, o aluno também não consegue compreender esse aspecto.

No mesmo grupo, os alunos continuam assistindo aos vídeos sem conseguir estabelecer relações com modelos atômicos, como o de Dalton, que no vídeo era representado por esferas de diferentes tamanhos que se uniam para formar a molécula de água. Os alunos parecem não ter assimilado as representações dos modelos atômicos utilizados. Apenas a molécula de água foi notada pelos alunos.

"Estrutura da molécula de água, a luz e a primeira os elétrons.” (G3A2)

“Elétrons, água.” (G3A4)

No experimento do teste de chama, em um primeiro momento, alguns alunos não conseguem estabelecer relação entre os vídeos sobre modelos atômicos e o experimento do teste de chama. Um grupo quis identificar os elementos presentem na solução por meio de reações químicas.

“Cara, e se a gente misturar as duas soluções?” (G2A2)

"Se isso aqui for sulfato de cobre...e isso aqui for hidróxido de sódio (solução incolor)...sulfato de sódio...é solúvel?" (G2A4)

Após reler as mensagens no rótulo dos balões volumétricos contendo as soluções, os alunos começam a estabelecer alguma relação com os vídeos. No geral, os alunos tentam estabelecer equilibrações INTER e, com a ajuda do professor, conseguem chegar a esse ponto.

"Será que, no caso, teria que fazer um teste de chama? As vezes...porque tem um gás ali...pela luz. (G2A4)

\section{“Alguma coisa a ver com a chama” (G1A1)}

"É, se for aquela do vídeo lá...com energia...quando voltar, emite luz" (G1A2)

Nesse sentido, em alguns momentos da aventura, o Short ARG precisa de ações em tempo real do professor, logo que observa as dificuldades dos alunos, fazendo com que eles não percam o interesse pela aventura, pelo fato de não conseguir avançar diante de obstáculos. Grande parte dos alunos afirmou nunca terem feito tal experimento e mostram estar bastante impressionados após visualizar a cor das chamas.

“Ohh..vermelho” (G3A1)

"Ó, ficou verde" (G3A3)

Ao longo da discussão percebemos alguns erros conceituais, alguns deles os próprios alunos, após uma reflexão, voltaram atrás.

"Como é que você faz um teste de chama? Não é a substância no estado sólido?(G2A1)

No experimento da separação de misturas os alunos mostraram que conhecem os métodos, mas não se preocuparam muito com a questão da perda de material no planejamento da ordem de separação dos componentes da mistura ao propor a ordem dos métodos de separação.

$$
\text { “Adiciona água, filtra, tira o ferro, depois a brita...” (G2A4) }
$$

No que diz respeito à elaboração do $\mathrm{ARG}$, faz-se necessário observar algumas questões para que o jogo possa cumprir sua função pedagógica, promovendo um equilíbrio entre a função lúdica e a função educativa, mantendo o foco do aluno na aventura, permitindo 
a liberdade, a voluntariedade e a argumentação, de forma natural. É preciso se reunir com os alunos antes da aventura, deixando claros os objetivos do ARG e da aventura.

O cuidado com os instrumentos de coleta de dados deve sempre estar presente. Em nossa aventura, tivemos problemas com os áudios e os vídeos dos alunos, pois os smartphones eram diferentes, o que fez com que o pesquisador tivesse que procurar na rede vários softwares conhecidos como "codecs" para conseguir ouvir os áudios ou visualizar os vídeos. Recomendamos que antes da aventura o professor orientador solicite aos alunos que façam download de softwares específicos para gravação de áudio como o "gravador de voz avançado".

Outra questão que merece atenção trata dos locais percorridos pelos grupos durante a aventura. No decorrer da aventura, alguns grupos ocuparam um mesmo local, o que fez com que grupos que estavam mais atrasados não pudessem visualizar o que outros grupos faziam, assim, quando eles chegaram ao mesmo ponto da aventura, deixaram de discutir como resolver tal situação, pois já tinham uma ideia do que fazer. Recomendamos que existam espaços distintos para que os grupos não visualizem eventos pelos quais passarão no futuro.

Recomendamos que haja um ponto de internet disponível para que os alunos possam ter livre acesso à rede, sempre que necessário. Caso não haja a disponibilidade, pelo menos um aluno do grupo deve ter acesso à rede. Caso nenhum aluno tenha acesso à rede, o professor orientador precisa realizar todas as pesquisas solicitadas pelos alunos.

No que diz respeito à evolução da regra, Soares $^{4}$ afirma que um bom jogo deve permitir a evolução da regra no sentido da melhora de alguns aspectos relacionados a ela. Quanto mais o jogo evolui suas regras, mais ele atinge seu objetivo enquanto jogo pedagógico, promovendo o divertimento, o prazer, a cooperação, as relações humanas e gerando aprendizagem.

Em termos dos aspectos referentes ao uso da experimentação, observamos uma baixa preocupação com aspectos quantitativos. Aconteceram alguns erros relativos ao experimento de determinação de densidades, como a precisão na medida obtida, ou ainda, medições indevidas de meniscos, utilização de frascos graduados, como provetas maiores e menos precisas, imersão de objetos como pinças no líquido, entre outros.

Os erros conceituais e de linguagem encontrados, bem como as discussões conceituais, denotam a importância do Short ARG como instrumento de avaliação diagnóstica. Luckesi ${ }^{21}$ afirma que para que a avaliação escolar possa assumir de fato sua função, a de transformação social, faz-se necessário o resgate de sua função diagnóstica. Para não ser autoritária e conservadora, a avaliação terá de ser diagnóstica, ou seja, deverá ser o instrumento dialético do avanço, terá de ser o instrumento da identificação de novos rumos. Enfim, terá de ser o instrumento do reconhecimento dos caminhos percorridos e da identificação dos caminhos a serem perseguidos. ${ }^{24}$

Hayd $t^{25}$ afirma que a avaliação diagnóstica deve ser realizada já no início do ano letivo ou do curso, isso traz uma identificação da turma, conhecendo sua realidade, seus conhecimentos e habilidades, podendo preparar estratégias através do planejamento de suas aulas de forma a contribuir para novas aprendizagens. Concordamos com a autora, entendendo que a avaliação diagnóstica também pode ser utilizada no decorrer do curso, em todas as etapas do currículo escolar, sempre que necessário, para compreender o quanto os alunos progrediram durante um determinado tempo. É importante que o professor tenha esse controle, pois como as turmas são muito heterogêneas, alguns alunos aprendem com mais facilidade do que outros. ${ }^{25}$

Dessa forma, o Short ARG funciona muito bem como um instrumento de avaliação diagnóstica e também formativa. Ao mesmo tempo em que, durante a aventura, os conceitos errôneos eram detectados, o professor discutia com os alunos tais conceitos, no sentido de melhorar sua discussão, o que torna o processo também formativo.

No entanto, confirmamos o ARG como um jogo pedagógico em sua principal característica, a de diagnosticar, de maneira leve e sem pressão, eventuais erros conceituais nos estudantes, o que nesse caso, de nível superior, também é preocupante, quando entendemos que os alunos já haviam cursado disciplinas básicas dos cursos de química, bem como disciplinas básicas de laboratório. É por meio da avaliação diagnóstica que se pode discutir os conceitos de maneira a construir conjuntamente o conhecimento.

\section{CONCLUSÕES}

Na elaboração de um Short ARG faz-se necessário observar alguns critérios para que a aventura possa cumprir seus objetivos. É importante pensar os lugares em que os alunos realizarão a aventura, de modo a não permitir que eles frequentem um mesmo ambiente e não vejam o que o outro grupo faz. Quando isso ocorreu, percebeu-se que os alunos deixavam de discutir os conceitos, copiando o que o outro grupo havia feito, comprometendo o objetivo da aventura.

Como o jogo utiliza as tecnologias, faz-se necessário que pelo menos um componente do grupo possua um smartphone com acesso à internet, o recomendável é disponibilizar um ponto de internet para que os alunos possam acessar, de acordo com suas demandas, a rede. A padronização dos aplicativos utilizados como gravadores de voz e leitores de QRCODE facilita a coleta de dados por parte do professor orientador.

Pode-se afirmar que o jogo permitiu aos alunos expor suas concepções acerca dos fenômenos de forma clara e natural. O caráter lúdico do jogo esteve presente em todos os momentos da aventura. $\mathrm{O}$ Short ARG se apresentou como importante estratégia de diagnóstico, evidenciando dificuldade com o vocabulário científico, em especial dos conceitos relativos à química, a visão simplista dos conceitos discutidos, a dificuldade em conseguir contextualizar o conceito e uma falta de preocupação com questões quantitativas relacionadas à experimentação.

A partir desse diagnóstico, o professor pode trabalhar os conceitos em sala de aula de forma a suprimir as lacunas existentes e promover um aprendizado no qual os alunos possuam os elementos necessários para entender de fato os conceitos discutidos, sua contextualização e aplicação prática.

\section{REFERÊNCIAS}

1. Chateau, J.; O Jogo e a Criança, Summus Editora: São Paulo, 1984.

2. Piaget, J.; A Formação do Símbolo na Criança: imitação, jogo, sonho, imagem e representação, Azhar Editores: Rio de Janeiro, 1972.

3. Brougere, G.; O Jogo e a Educação, Art Med: Porto Alegre, 1998.

4. Soares, M. H. F. B.; Jogos e Atividades Lúdicas para o Ensino de Química, 2a . ed., Kelps: Goiânia, 2015.

5. Kishimoto, T. M. Em Jogo, Brinquedo, Brincadeira e a Educação; Kishimoto, T. M., ed.; $4^{a}$ ed., Cortez: São Paulo, 1996, cap.1.

6. Cleophas, M. G.; Cavalcanti, E. L. D.; Soares, M. H. F. B. Em Didatização Lúdica no Ensino de Química/Ciências: teorias de aprendizagem e outras interfaces; Cleophas, M. G., Soares, M. H. F. B., eds.; LF Editorial: São Paulo, 2018, cap. 1.

7. Cleophas, M. G. P.; Tese de Doutorado, Universidade Federal Rural de Pernambuco, Brasil, 2015.

8. Chechi, A.; Cleophas, M. G.; Revista Debates em Ensino de Química 2019, 5, 31 .

9. Cleophas, M. G.; Chechi, A.; Revista Tecnologias na Educação 2018, $28,1$.

10. Cleophas, M. G.; Cavalcanti, E. L. D.; Leao, M. B. C.; Ensenanza de Las Ciencias, 2017, Extra, 3957. 
11. Andrade, L. A.; Revista Lumina, 2006, 9, 41.

12. Oliveira, T. M.; Marinho, K. A. R.; Signo y Pensamiento, 2010, 29, 538.

13. Bolsignore, E.; Hansen, D.; Kraus, K.; Playing for Real Designing Alternate Reality Games for Teenagers in Learning Contexts, IDC: New York, 2013.

14. Shaffer, D. W.; Squire, K. R.; Halverson, R.; Gee, J. P.; The Phi Delta Kappan, 2005, 87, 104.

15. Piaget, J.; Relações Entre a Afetividade e a Inteligência no Desenvolvimento Mental da Criança, Wak: Rio de Janeiro, 2014.

16. Lefrançois, G. R.; Teorias da Aprendizagem: o que o professor disse, Cengage Learning: São Paulo. 2016.

17. Piaget, J. A.; Equilibração das Estruturas Cognitivas: problema central do desenvolvimento, Zahar Editores: Rio de Janeiro, 1976.
18. Aguiar Jr., O.; Caderno Catarinense de Ensino de Física 1999, 16, 72.

19. Triviños, A. N. S.; Introdução à Pesquisa em Ciências Sociais: a pesquisa qualitativa em educação, Atlas: São Paulo, 2013.

20. Bardin, L.; Análise de conteúdo, Almedina: São Paulo, 2016.

21. Franco, M. L. B.; Análise de Conteúdo, $4^{\mathrm{a}}$ ed., Liber: Brasília, 2012.

22. Suart, R. C.; Marcondes, M. E. R.; Ciência e Cognição 2009, 14, 50.

23. Melo, M. R.; Lima Neto, E. G.; Quim. Nova Esc. 2013, 35, 112.

24. Luckesi, C. C.; Avaliação da Aprendizagem Escolar: estudos e proposições, 22a ed., Cortez: São Paulo, 2011.

25. Haidt, R. C. C.; Curso de Didática Geral, Ática: São Paulo, 1994. 